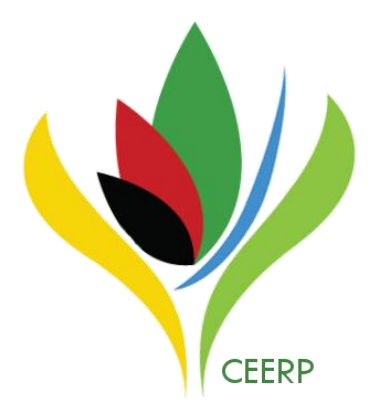

Centre for Energy Economics Research and Policy

\title{
Causes and Consequences of Oil Price Shocks on the UK Economy
}

Marco Lorusso and Luca Pieroni

Heriot-Watt University

Edinburgh, Scotland

EH14 4AS

ceerp.hw.ac.uk 


\title{
Causes and Consequences of Oil Price Shocks on the UK Economy
}

\author{
Marco Lorusso* \\ Luca Pieroni ${ }^{\dagger}$ \\ Heriot-Watt University \\ University of Perugia
}

November 2015

\begin{abstract}
In this paper, we assess the impact of oil price fluctuations on the UK economy. We use an empirical strategy which allows us to decompose oil price changes from the underlying source of the shock. Our results show that, since the mid-1970s, oil price movements have been mainly associated with shocks to oil demand rather than oil supply. We also find that the consequences of oil price changes on UK macroeconomic aggregates depend on the different types of oil shocks. While increases in global real economic activity do not depress the UK economy in the short run, shortfalls in crude oil supply cause an immediate fall in GDP growth. In addition, since monetary policy depends on the nature of the shock hitting the oil market, domestic inflation increases following a rise in the real oil price. Finally, our results also show that in response to oil price increases, the government deficit decreases.
\end{abstract}

JEL Classification: E31, E32, Q41, Q43, Q48.

Keywords: Oil Price Shocks, Vector Autoregressions.

\footnotetext{
${ }^{*}$ Corresponding author. E-mail: marco.lorusso@pet.hw.ac.uk, Institute of Petroleum Engineering, Heriot-Watt University, Conoco Centre, Edinburgh EH14 4AS, Tel: +44 (0)131 451 4578 .

${ }^{\dagger}$ E-mail: luca.pieroni@unipg.it, Department of Political Science, University of Perugia, Via Pascoli 20, 06123, Perugia, Italy, Tel. +39 0755855280 .
} 


\section{Introduction}

Since the dramatic oil price spikes of the 1970's, and the consequent global recession, economists have analysed oil price fluctuations in order to understand their economic impact. In this regard, a large number of studies have investigated the macroeconomic effects of oil price shocks (see, Hamilton, 1983 and 2003; Burbidge and Harrison, 1984; Bernanke et al., 1997; Papapetrou, 2001; Lee and Ni, 2002; Bernanke, 2004; Barsky and Kilian, 2004; Peersman, 2005; Blanchard and Galí, 2007; Kilian, 2008 and 2009; Peersman and Van Robays, 2009; Lombardi and Van Robays, 2011; Morana, 2013).

Although these studies have found a negative correlation between oil price increases and economic performance, a strong divergence appeared in the analysis of the causes of oil price fluctuations. The assumption of the oil price as an exogenous driver to economic fundamentals, which does not distinguish between the different sources of oil price fluctuations ${ }^{1}$, was shown inappropriate by Kilian (2009). This author suggested important evidences of a reverse causality from macroeconomic aggregates to oil prices and also showed that oil prices are driven by structural demand and supply shocks which have direct effects on the macroeconomy.

In this paper, we aim to analyse the impact of oil price changes on the UK economy. We use a structural vector autoregression (VAR) approach and adopt a two-stage method in order to identify and estimate our model. In the first stage, we assess the causes of oil price changes depending on the underlying source of the shock; that is, we investigate whether the oil price has been driven by a supply or a demand disturbance. In the second stage, we examine the effects of the structural shocks estimated in stage 1 on a set of UK macroeconomic aggregates such as output growth, inflation, nominal interest rate and government deficit.

The empirical strategy adopted is in accordance with the approach of Kilian (2009), which endogenizes the effects of oil price, and is fully consistent with the

\footnotetext{
${ }^{1}$ See, for example Hamilton (2003).
} 
theoretical framework based on Dynamic Stochastic General Equilibrium (DSGE) models developed by Bodenstein et al. (2008), Nakov and Pescatori (2010), Nakov and Nuño (2011), Bodenstein et al. (2011), Bodenstein and Guerrieri (2011) and Bodenstein et al. (2012). ${ }^{2}$

The analysis developed in this paper also focuses on the demand side of the oil market. It is worth noting that the traditional emphasis on physical oil supply shocks in explaining oil price fluctuations is misplaced as provided by a large number of studies such as Barsky and Kilian (2002), Kilian (2008), Apergis and Miller (2009), Basher et al. (2012), Kilian and Murphy (2012) and (2014), Kilian and Hicks (2013), Baumeister and Peersman (2013).

Hitherto, most of the papers analysing the relationship between oil and the macroeconomy have focused on the United States. There have also been a few cross-country studies. For example, Berument et al. (2010) showed that oil price increases have positive effects on output growths of several Middle East and North African countries (such as Algeria, Iran, Iraq, Kuwait, Libya, Oman, Qatar, Syria, and the United Arab Emirates). Baumeister et al. (2010) found a smaller effect on Euro Area GDP of oil supply shocks than in the United States, although similar effects were found from oil shocks driven by world activity in the two areas. Peersman and Van Robays (2012) compared the macroeconomic effects of several types of oil shocks across a set of advanced economies and found that these effects differ significantly depending upon the underlying driver of the price change. More recently, the paper of Aatstveit et al. (2015), using a FAVAR model, examines the importance of demand from emerging and developed countries as drivers of the real oil price.

In contrast to the above literature, our paper focuses on the response of the UK macroeconomy to global oil price changes. We expect the United Kingdom to be a very interesting study case as it is the largest producer of oil in the European

\footnotetext{
${ }^{2}$ Using a DSGE model, Milani (2009) proposed an innovative approach in order to investigate the effects of oil prices on US macroeconomic aggregates. In particular, this author emphasized the changing effect that oil prices have on the formation of economic agents' expectations and the role of learning.
} 
Union. In particular, we analyse how the effects of oil price fluctuations on the UK economy may depend on the nature of the underlying shock. Our structural VAR model distinguishes between oil price changes caused by exogenous disruptions in oil production, oil demand shocks driven by global real economic activity and oil market-specific demand shocks associated with the uncertainty about future supply.

The sample of our analysis covers the period 1976-2014. In this regard, an additional contribution is to estimate the VAR model with monthly data. Indeed, our empirical set up heavily relies on delay restrictions that are economically plausible only at monthly frequency. As far as the causes of oil price shocks are concerned, our results confirm the findings of Kilian (2009) for the sample 1976-2007, adding the explaination of oil price variations in recent years. We find that, since the mid-1970s, most large and persistent fluctuations in the real price of oil have been associated with the cumulative effects of oil demand rather than oil supply shocks. The fact that flow supply disruptions have had small effects on the real oil price does not mean that political events in the Middle East do not matter. On the contrary, these events have affected the real oil price by shifting expectations about future shortages of oil supply relative to oil demand.

Turning to the consequences of oil price shocks on the UK economy, we find that oil supply disruptions induce an immediate fall in domestic GDP growth and cause a sustained increase in domestic inflation. Our estimates show that increases in aggregate demand, initially, have a negligible effect on UK output growth but in the long term they tend to depress it. Although the overall performance of the UK economy deteriorates, after an increase in the oil price, UK public finances improve. In addition, our impulse response analysis indicates that the Bank of England responds differently to oil price fluctuations associated with unanticipated booms in oil demand compared to oil price changes due to unexpected oil supply disruptions. Indeed, the nominal interest rate increases after both aggregate demand shocks and oil market-specific demand shocks occur, whereas negative 
shocks to the oil supply induce the Bank of England to reduce its policy interest rate.

The rest of the paper is structured as follows. In the next section we discuss the specification and identification of our empirical model. Section 3 discusses the results distinguishing between the causes of oil price changes and the effects of oil price fluctuations on the UK economy. Section 4 concludes suggesting improvements for future researches.

\section{The Empirical Framework}

We estimate the causes and consequences of oil price shocks in two distinct stages. Firstly, we use a structural VAR (SVAR) framework to capture supply and demand conditions in the oil market. Accordingly, we apply the identifying assumptions on the relationships between the world variables in order to recover three structural shocks affecting oil prices: oil supply shocks, aggregate demand shocks and oil market-specific demand shocks (or precautionary demand shocks). In particular, oil supply shocks are shocks to current availability of crude oil. Aggregate demand shocks affect the current demand for crude oil coming from changes in the global business cycle. Oil market-specific demand shocks are those driven by shifts in the precautionary demand for oil; they come from the uncertainty about shortfalls of expected supply relative to expected demand. The latter shock includes the holdings of oil inventories as insurance against oil supply disruptions.

In stage 2, we assess the impact of structural innovations, estimated in stage 1 , on several UK macroeconomic aggregates such as real GDP growth, CPI inflation, the nominal interest rate and the real government deficit. The use of two-stage procedure presents two advantages. Firstly, our approach enables us to keep the number of variables in our SVAR manageable (less than four) given the computational requirements associated with estimating larger VARs. Secondly, separating the process of identifying structural shocks in the oil market removes the need to employ further identification restrictions on the UK macroeconomic 
aggregates.

\subsection{Modelling the Causes of Oil Price Shocks: a World SVAR}

\subsubsection{Data}

We consider monthly data for the sample period 1976:1-2014:12. ${ }^{3}$ In order to estimate the World structural VAR, we use the percentage change of global crude oil production $\left(\Delta \operatorname{prod}_{t}\right)$ obtained by the log differences of world crude oil production in millions per barrels pumped per day (averaged by month). ${ }^{4}$

The index of global real economic activity $\left(r e a_{t}\right)$ is a measure of the component of worldwide real economy activity which drives demand for industrial commodities in global markets (Kilian, 2009). This index is based on dry cargo single voyage ocean freight rates. As argued by Klovland (2004), world economic activity is the most important determinant of the demand for transport services. Thus, following the original idea of Kilian (2009), increases in freight rates are indicators of strong cumulative global demand pressures.

The real price of oil $\left(r p o_{t}\right)$ is obtained from the series of the US crude oil imported acquisition cost by refiners. There are at least three motivations for this choice with respect to the Europe Brent spot price. Firstly, as we can observe from Figure 1, the Europe Brent spot price and US crude oil imported acquisition cost by refiners have very close patterns during the period considered. Secondly, the series of US crude oil imported acquisition cost by refiners is available at monthly frequency back to January $1974 .^{5}$ As we will explain below, the monthly frequency of this data series is crucial for the identification assumptions of our SVAR. Thirdly, the longer sample size of this series allows us to consider the relevant episodes that occurred during the 1970's.

\footnotetext{
${ }^{3}$ We use the sample period 1974:1-1975:12 as training sample for our estimates.

${ }^{4}$ See Appendix A for a detailed description of data sources and the construction of the series used to estimate the World SVAR.

${ }^{5}$ On the contrary, the monthly series of the Europe Brent spot price is available only from May 1987.
} 


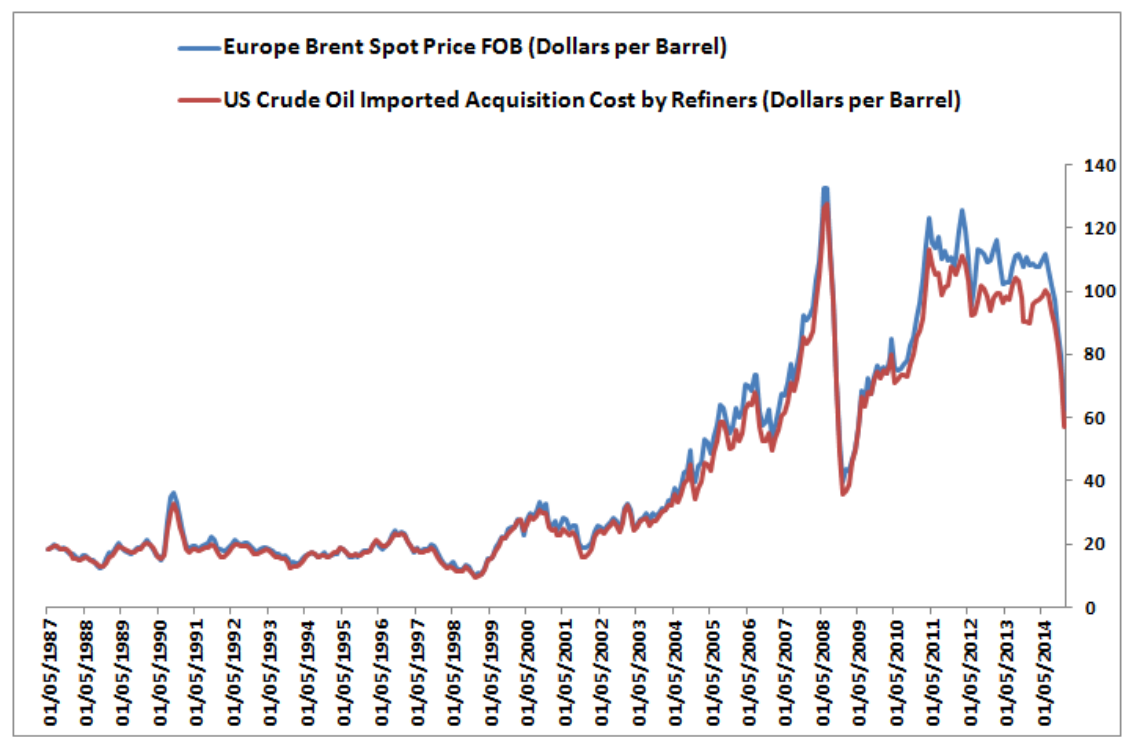

Figure 1: US Crude Oil Imported Acquisition Cost by Refiners and Europe Brent Spot Price, May 1987 to December 2014

Source: US Department of Energy.

Here, we show the nominal and real oil price series at monthly frequency from the period January 1974 to December 2014 (Figure 2). As we can observe from the graph, the crude oil price rose persistently from the end of the 1970's to the mid-1980's. Except for the peak episodes observed in 1990-1991 and 1999-2000, the oil price remained fairly stable at around $\$ 20$ per barrel from 1986 until the end of 2001. Later that year, the path of oil price steepened sharply until the end of 2008, and this surge was followed by an even more spectacular collapse. In 2011, the oil price went back to the level achieved in 2007-2008. Finally, we observe a plunge in the oil price at the end of 2014 . 


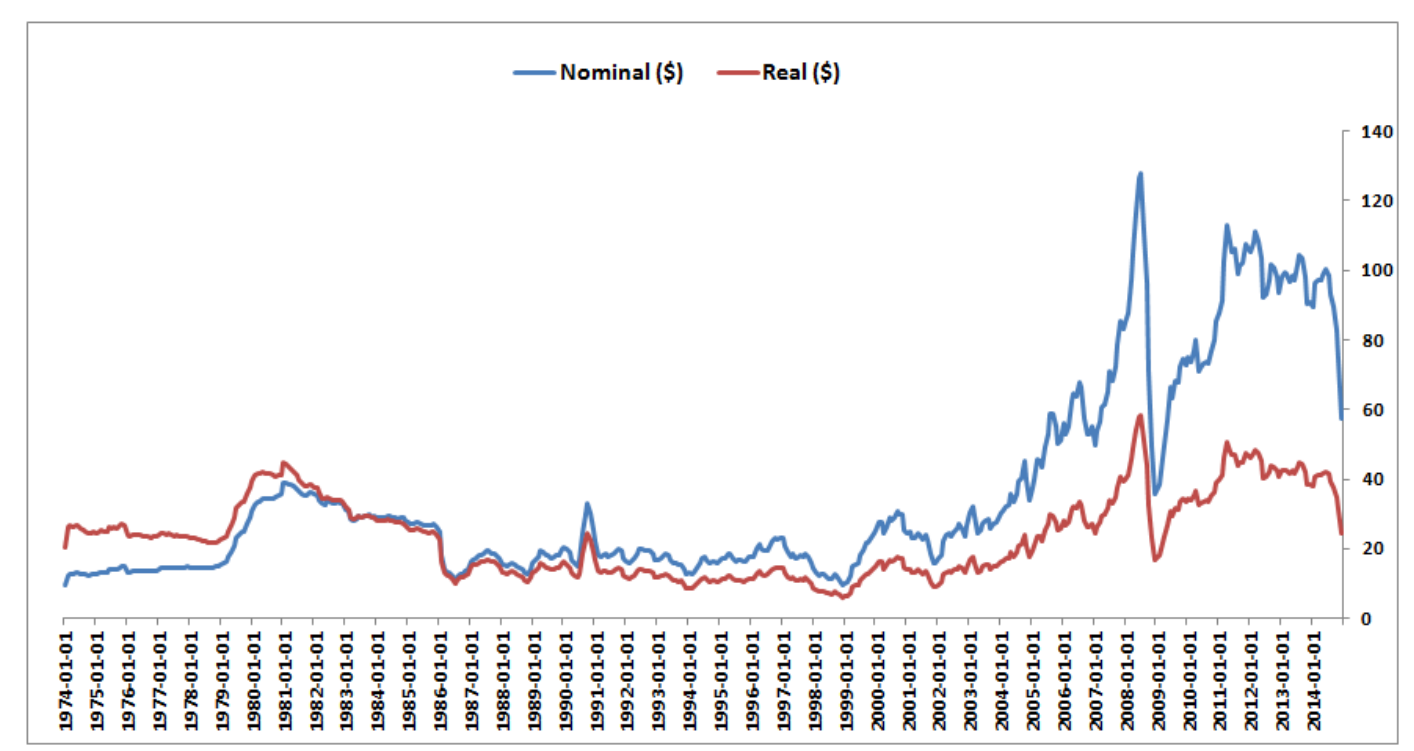

Figure 2: Real and Nominal Oil Prices (US Crude Oil Imp. Acq. Cost by Refiners)

Source: US Department of Energy and US Bureau of Economic Analysis.

\subsubsection{Specification and Identification of the Model}

As a benchmark specification for our model, we adopt a SVAR, whose reduced form is defined by the following dynamic equation:

$$
\mathbf{B}_{0} \mathbf{y}_{t}=\mathbf{c}_{t}+\sum_{l=1}^{24} \mathbf{B}_{l} \mathbf{y}_{t-l}+\mathbf{u}_{t}
$$

where $\mathbf{y}_{t}=\left(\Delta \operatorname{prod}_{t}, r e a_{t}, r p o_{t}\right)^{\prime}$ indicates the three-variable vector of variables specified above, $\mathbf{c}_{t}$ is a vector of constants and $\mathbf{u}_{t}$ denotes the vector of reducedform innovations. As an identification strategy, we adopt a Cholesky factorization so to recover the vector of structural shocks $\varepsilon_{t}$ from the reduced-form error $\mathbf{u}_{t}$ in (1), according to the following scheme:

$$
\boldsymbol{\varepsilon}_{t}=\left[\begin{array}{c}
\varepsilon_{t}^{\Delta \text { prod }} \\
\varepsilon_{t}^{r e a} \\
\varepsilon_{t}^{r p o}
\end{array}\right]=\left(\begin{array}{ccc}
\alpha_{11} & 0 & 0 \\
\alpha_{21} & \alpha_{21} & 0 \\
\alpha_{31} & \alpha_{32} & \alpha_{33}
\end{array}\right)\left[\begin{array}{c}
u_{t}^{\text {oil supply shock }} \\
u_{t}^{\text {aggregate demand shock }} \\
u_{t}^{\text {oil market-specific demand shock }}
\end{array}\right]
$$


The Cholesky ordering in (2) corresponds to assuming the following set of conditions. Firstly, crude oil supply shocks are defined as unpredictable innovations to global oil production, that is, oil demand shocks $\left(u_{t}^{\text {aggregate demand shock }}\right.$ and $\left.u_{t}^{\text {oil market-specific demand shock }}\right)$ do not influence crude oil supply $\left(u_{t}^{\text {oil supply shock }}\right)$ in the same month. This assumption is plausible since adjusting oil production is costly for oil producer countries and because the state of the crude oil market is difficult to forecast in the very short run. Hence, oil producer countries tend to respond slowly to oil demand shocks.

Secondly, shocks to global real economic activity that are not explained by oil supply shocks are identified as shocks to global demand for industrial commodities. We define these shocks as aggregate demand shocks. We assume that shocks to oil market-specific demand ( $\left.u_{t}^{\text {oil market-specific demand shock }}\right)$ do not influence global real economic activity $\left(u_{t}^{\text {aggregate demand shock }}\right)$ in the same month. In general, our assumption is reasonable because global real economic activity responds with a delay to oil price increases.

Finally, shocks to the real oil price that are not explained by oil supply shocks or aggregate demand shocks by construction reflect changes in the demand for oil in contrast to changes in the demand for all industrial commodities. We define these shocks as oil market-specific demand shocks. In particular, these shocks represent the fluctuations in precautionary demand for oil due to uncertain future oil supply.

We estimate the VAR reduced-form equation (1) using least squares. The resulting estimates are used to construct the SVAR model. We adopt the inference method used by Gonçalves and Kilian (2004) which implies a recursive-design wild bootstrap with 2,000 replications. ${ }^{6}$

\footnotetext{
${ }^{6}$ This method is successful in dealing with conditional heteroskedasticity of unknown form in autoregressions. It is well known that there is evidence of conditional heteroskedasticity in the residuals of many estimated dynamic regression models involving monthly data and, in this case, standard residual-based bootstrap methods of inference for autoregressions are invalidated by conditional heteroskedasticity.
} 


\subsection{Modelling the Consequences of Oil Price Shocks on the UK Economy}

Having identified the shocks and obtained the responses of our World variables to these shocks, we then estimate the impact of these structural innovations on the UK macroeconomic fundamentals. In particular, we use: growth rate of real GDP $\left(\Delta y_{t}\right)$, CPI inflation $\left(\pi_{t}\right)$, the short-term nominal interest rate $\left(\Delta r_{t}\right)$ and the real government deficit $\left(d_{t}\right) .{ }^{7}$ More specifically, we measure the effects of oil supply shocks, aggregate demand shocks and oil specific demand shocks on these UK macroeconomic aggregates adopting the following regressions:

$$
\begin{aligned}
\Delta y_{t} & =\alpha_{j}+\sum_{i=1}^{12} \gamma_{j i} \hat{\lambda}_{j t-i}+z_{j t} \\
\text { with } & : \quad j=1,2,3 \\
\pi_{t} & =\delta_{j}+\sum_{i=1}^{12} \eta_{j i} \hat{\lambda}_{j t-i}+v_{j t} \\
\text { with } & : \quad j=1,2,3 \\
\Delta r_{t} & =\theta_{j}+\sum_{i=1}^{12} \iota_{j i} \hat{\lambda}_{j t-i}+s_{j t} \\
\text { with } & : \quad j=1,2,3
\end{aligned}
$$

and:

$$
\begin{aligned}
d_{t} & =\varphi_{j}+\sum_{i=1}^{12} \varkappa_{j i} \hat{\lambda}_{j t-i}+w_{j t} \\
\text { with } & : j=1,2,3
\end{aligned}
$$

Our model is based on quarterly data for $\Delta y_{t}, \pi_{t}, \Delta r_{t}$, and $d_{t}$ because some of the aggregate series of our analysis are not available at monthly frequency or have

\footnotetext{
${ }^{7}$ Appendix A provides a detailed description of data sources and the construction of the series used to estimate the consequences of oil price shocks on the UK economy.
} 
a short time span. ${ }^{8}$ Our choice of using all the data series at quarterly frequency allows us to easily compare the estimated results of each macroeconomic aggregate.

Thus, in equations (3)-(6), $\hat{\lambda}_{j t}$ represents the measure of quarterly shocks (estimated in model (1)) constructed by averaging the monthly structural innovations for each quarter:

$$
\begin{aligned}
\hat{\lambda}_{j t} & =\frac{1}{3} \sum_{i=1}^{3} \hat{u}_{j, t, 1} \\
\text { with } & : \quad j=1,2,3
\end{aligned}
$$

where $\hat{u}_{j, t, 1}$ indicates the estimated residual for the $j$-th structural shock in the $i$ th month of the $t$ th quarter of the sample. ${ }^{9}$ In equations (3)-(6) the impulse response coefficients correspond to $\gamma_{j i}, \eta_{j i}, \iota_{j i}$, and $\varkappa_{j i}$, respectively. The number of lags is determined by the maximum horizon of the impulse response function, which is set to twelve quarters. Finally, in equations (3)-(6), $z_{j t}, v_{j t}, s_{j t}$ and $w_{j t}$ are potentially serially correlated errors. In order to deal with possible serial correlation in the error term we use block bootstrap methods. Following the usual empirical strategy, all our estimated results are obtained with block size 4 and 20,000 bootstrap replications.

Our regression model (3)-(6) assumes that, within a given quarter, there is no feedback from $\Delta y_{t}, \pi_{t}, \Delta r_{t}$, and $d_{t}$ to $\hat{\lambda}_{j t}, j=1,2,3$ such as we can assess their effects on UK macroeconomic aggregates. The assumption that oil supply shocks, aggregate demand shocks and oil market-specific demand shocks are exogenous to GDP growth, CPI inflation, nominal interest rate and government deficit is based on the fact that the United Kingdom is "small" in the sense that movements in UK economic variables have no effect on world variables. In fact, although the United Kingdom produces oil, its average share of oil production in the period

\footnotetext{
${ }^{8}$ In particular, for the sample period 1976:1-2014:12, data at monthly frequency is available only for the short-term nominal interest rate. The series of the CPI inflation starts in 1988:1, whereas the one of real government deficit only in 1993:1. Moreover, we do not use interpolated real GDP growth data because interpolation is known to cause spurious dynamics.

${ }^{9}$ These quarterly averages are not exactly uncorrelated, but their correlation is so low that they can be treated as uncorrelated.
} 
1976-2014 was 3\% with a peak of 5\% from 1984 to 1986 and it was $1 \%$ in 2014 according to the statistics of US Energy Information Administration (Monthly Energy Review). Similarly, UK petroleum consumption has been on average $3 \%$ of world consumption during the period 1976-2014 (US Energy Information Administration - Monthly Energy Review).

\section{Results}

In this section, we show the estimation results of our empirical model. We start by discussing the estimates concerning the causes of oil shocks (Section 3.1) and successively we focus on the consequences of oil shocks on the UK economy (Section $3.2)$.

\subsection{Causes of Oil Shocks: Estimates}

Figure 3 shows the historical evolution of the structural shocks considered in our model for the period 1976-2014. Our analysis focuses on the episodes associated with the major changes in the real oil price. Our estimated results confirm the findings of Kilian (2009) for the sample 1976-2007, although we are able to explain oil price variation in recent years (2008-2014).

From Graph (a), we do not observe any oil supply disruption corresponding to the Iranian Revolution occurring in 1978-1979. Accordingly, the reductions of oil supply due to the Iranian Revolution were more than offset by increases in production from other oil producer countries.

Differently, in coincidence with the Iran-Iraq War in 1980, we find evidence of a substantial shortfall in crude oil supply.

Graph (b) shows that repeated large positive shocks to global aggregate demand occurred in 1978, 1979 and 1980, while from Graph (c), we observe a large unanticipated increase of oil market-specific demand during 1979. Indeed, episodes of Iranian Revolution, the Iranian hostage crisis and the Soviet invasion of Afghanistan all created concern about the future availability of oil supply from 
the Middle East and induced a higher precautionary demand for oil.

Focusing on the most recent years (2002 to mid-2008), the large increase in the real oil price was driven by a series of positive aggregate demand shocks associated with shifts in global real economic activity (Graph (b)). Interestingly, during the same period, we find that oil supply shocks played a negligible role in oil price fluctuations (Graph (a)). We also observe that, at the end of 2008, the plunge in the real price of oil reflected the falls of aggregate demand and oil market-specific demand, respectively (Graphs (b) and (c)).
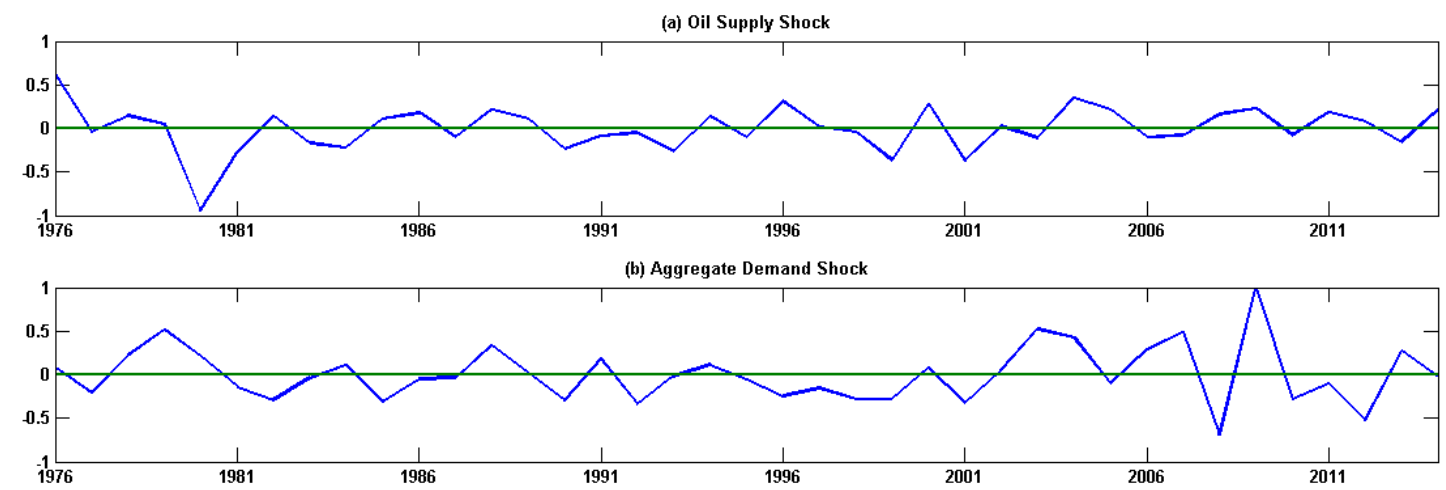

(c) Oil Market-Specific Demand Shock

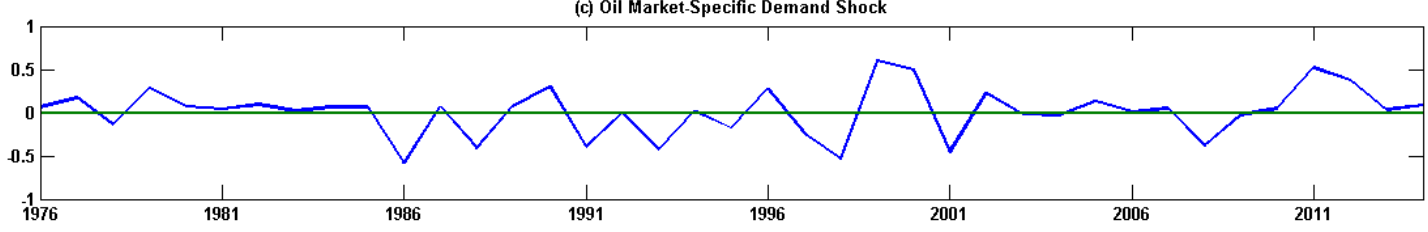

Figure 3: Historical Evolution of the Structural Shocks, 1976-2014

Note: Annual frequency average of structural residuals implied by the SVAR model (1).

The last episode that we analyse concerns the surge in the oil price that occurred from 2011 to mid-2014. As we can see from Graph (c), there is evidence of a series of positive oil market-specific demand shocks. Indeed, serious concerns about political instability in the Middle East have emerged with protests taking place in Tunisia and Egypt. Some signs of civil unrest have also appeared in 
Lebanon, Algeria and Yemen. All these events have created concerns about future oil shortages in the Middle East. As Barrell et al. (2011) have argued, the repeated oil market-specific demand shocks which occurred in this period can also be explained by the sharp rise in investors' demand as the financial crisis unfolded, with investors pulling out of complex financial assets in search of a safer haven.

Figure 4 shows the impulse response analysis of global oil production, global real economic activity and the real price of oil to one standard deviation structural shocks. In particular, we normalize the signs of the shocks in order to induce an increase in the oil price.

Graph (a) shows that an unanticipated oil supply disruption implies an immediate strong reduction of global oil production. After one year, we observe a partial recovery of global oil production. This result is generally explained with the evidence that in the presence of a negative oil production shock in one region, producer countries of other areas in the World increase their production. From Graph (b), we see that an unanticipated oil supply disruption does not significantly affect global real economy activity, while causes a small and partially significant increase in the real price from fourth to seventh month (Graph (c)).

We note that an unexpected increase in aggregate demand implies an expansion of global oil production, that becomes significant three months after the shock occurs, a significant increase in the global real economic activity and a sharp, very persistent and statistically significant, increase in the real oil price (Graph (d), (e) and (f), respectively).

While an unanticipated expansion of oil market-specific demand does not influence global oil production, it causes a temporary increase in the global real economic activity, that is significant until the tenth month, and an immediate large increase in the real oil price (Graph (g), (h) and (i)). The last effect is very persistent and highly significant.

Our results confirm the findings of Kilian (2009) and Alquist and Kilian (2010). In particular, the most important result emerging from our IRF is that shortfalls 
in oil supply have small and partially significant effects on oil price changes. As argued above, oil supply disruptions in one region are compensated by increases of endogenous oil supply from other regions of the world. Accordingly, the question that arises is: how can one explain the large increases in the real oil price following the major political events in the Middle East? Figure 4 shows that the answer coincides with the sharp increases of precautionary demand for oil. These changes in precautionary demand are caused by shifts in expectations of future oil supply. Such expectations respond on impact to exogenous political events in the Middle East and cause a large increase in the oil price.
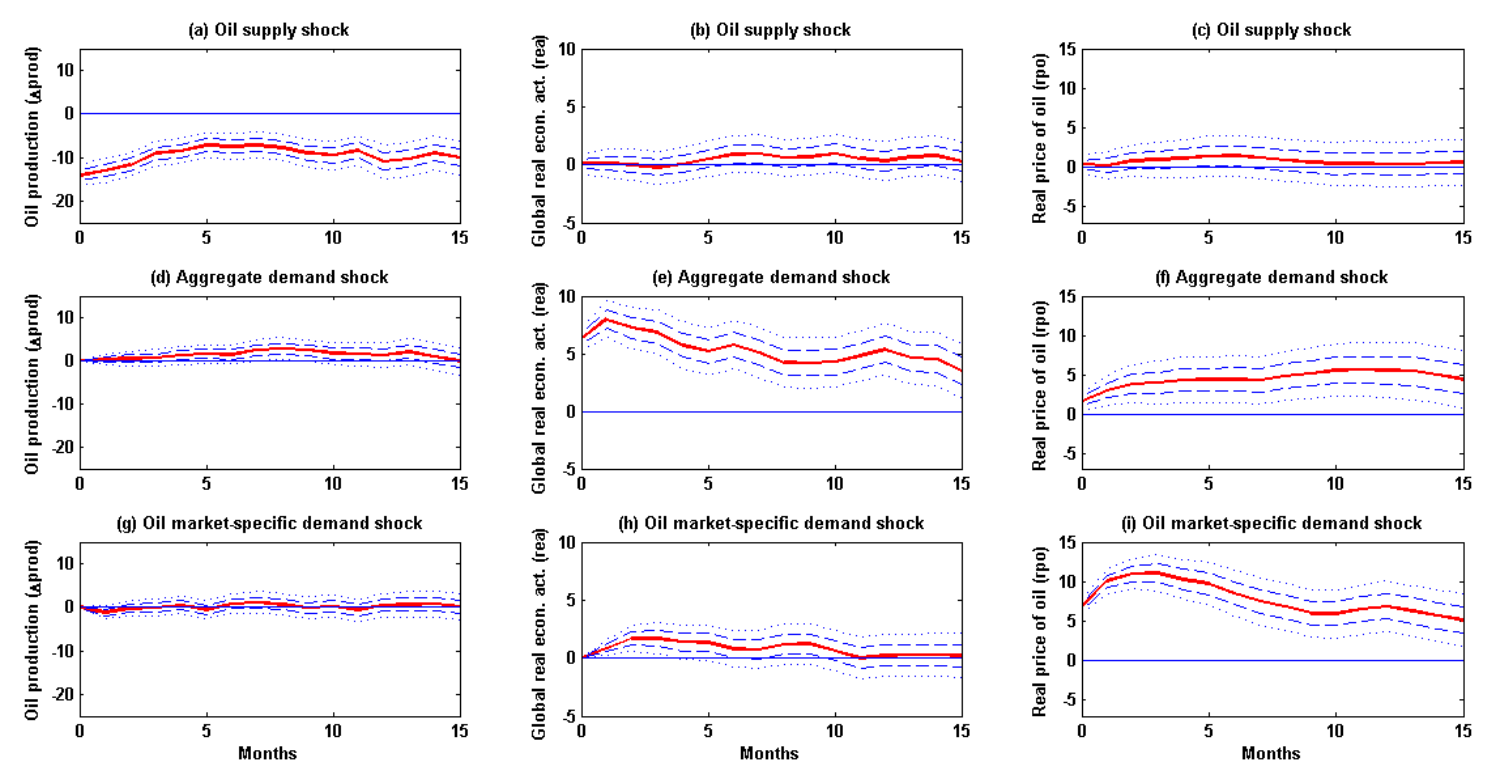

Figure 4: Impulse Response Analysis to One St. Dev. Shocks

Note: Solid red lines: point estimates; dash and dotted blue lines: one and two standard error bands, respectively.

The cumulative effects of oil demand and supply shocks on the real price of oil are shown in Figure 5. These results confirm the previous findings that oil supply shocks have played a small role in terms of determination of oil price, 
while aggregate demand shocks and oil market-specific shocks explain most of the variation in the oil price.

In particular, Graph (c) shows that the surge in the oil price in 1980 was caused by the increase in precautionary demand for oil whereas, during the 19801982 period, aggregate demand grew continuously, causing the rise in the oil price (Graph (b)). Consequently, we strengthen the conclusions the increase in the oil price that occurred in late 1979, which continued until 1985, was mainly caused by demand shocks, while during this period, oil supply shocks do not influence substantially oil price variation.

We also observe that the fall in the real price of oil that occurred in 1986 was mainly associated with the fall in oil market-specific demand. The increase of Saudi Arabia oil production following the fall of OPEC cartel in the late 1985 does not seem to explain the drop in the oil price in in 1986 (Graph (a)).

In 1990-1991, we note a large increase in the oil market-specific demand that caused the sharp increase in the oil price (i.e., precautionary demand for oil) in response to expected shortfalls in oil supply due to the Kuwait Invasion. The latter episode also caused a physical disruption in oil supply. Again, oil market-specific demand shock was the main cause of the oil price surge of 1999-2000 (Graph (c)).

Turning to more recent episodes of oil price fluctuations, we find that the increase in the oil price during the 2002-2008 period coincided with a very large swing in global real economic activity (Graph (b)). Indeed, during this period, there was sustained global demand pressure and the oil price increased more than other commodity prices. The latter effect occurred because the supply of crude oil supply stagnated between 2002 and 2008 (Graph (a)). At the end of 2008, the drop in oil price was associated with the fall in oil market-specific demand (Graph (c)).

We know that between 2011 and mid-2014 there has been a sustained increase in oil market-specific demand that pushed up the oil price and that this rise of precautionary demand for oil was associated with social and political instability in 
the Middle East and North African regions. In particular, the unrest sweeping Tunisia in early 2011 rapidly spread over into many surrounding countries, including major oil producers, such as Algeria and, most significantly, Libya. Clearly, instability in the region automatically raised worries of supply disruptions and possible oil shortage. Moreover, between 2011 and mid-2014, the worsening of the financial crisis tended to increase precautionary demand for oil (Barrell et al., 2011). Finally, the plunge in the oil price that started in mid-2014 seems to be associated with the decreases of both aggregate demand and oil market-specific demand.
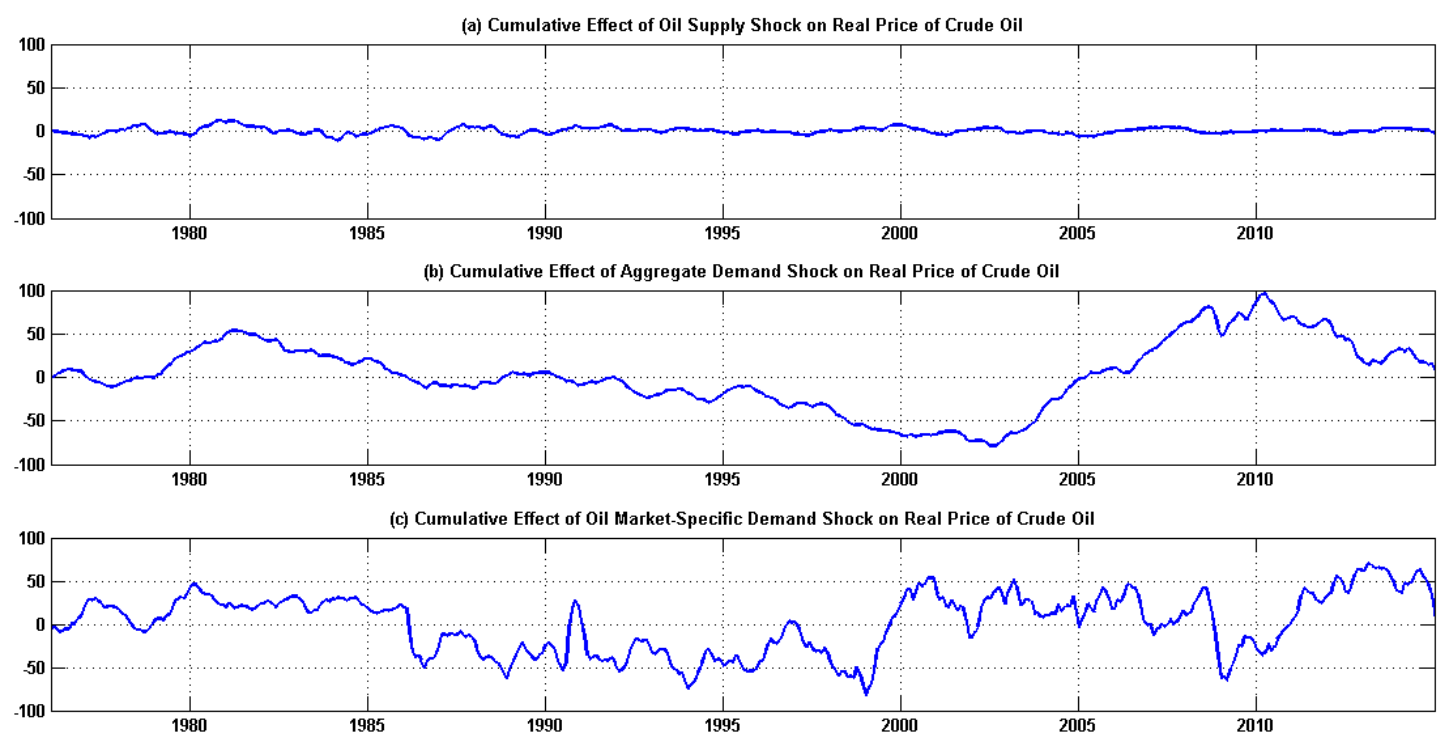

Figure 5: Historical Decomposition of Real Oil Price

Note: Estimation results obtained from the SVAR model (1).

Our analysis is in accordance with the results of Barsky and Kilian (2002) and Kilian (2009), which show that most large and persistent fluctuations in the real price of oil since the mid-1970s have been associated with the cumulative effects of oil demand rather than oil supply shocks. Moreover, our analysis contrasts with 
the traditional studies that suggest that all major fluctuations in the price of oil can be attributed to disruptions of oil supply triggered by political events occurred in the Middle East (Hamilton, 1983, 2003 and 2009).

The fact that flow supply disruptions have had small effects on the real oil price does not mean that political events in the Middle East do not matter. These events have affected the real oil price by shifting expectations about future shortages of oil supply relative to oil demand. As we explained above, in our model these expectations are captured by shocks to precautionary demand for oil, showing that oil market-specific demand shocks cause large fluctuations in the real oil price even when oil supply is unchanged.

\subsection{Consequences of Oil Shocks on the UK Economy: Estimates}

In this section, using our model specified according to equations (3)-(6), we analyse the effects of the identified shocks on UK macroeconomic variables: GDP growth, CPI inflation, the nominal interest rate, and the real government deficit.

We start by analysing the responses of domestic GDP growth and CPI inflation to these shocks as shown in Figure 6 (Graphs (a), (b), (c) and (d), (e) (f), respectively).

The response of GDP growth to oil supply disruptions is negative throughout all quarters. However, the one-standard error confidence intervals indicate that the negative response is significant only for the first five quarters. The response of GDP growth to aggregate demand expansions is positive, but is not statistically significant. Seven quarters after the shock occurs, it turns to negative and it becomes significant from the second year onwards. Instead, one-standard error confidence intervals indicate that the response of GDP growth to oil market-specific demand shock is not statistically significant at all horizons. There is only some evidence of a decline in GDP growth rate six quarters after the shock occurs.

Inspecting the inflation responses, we note that negative oil supply shocks lead to statistically significant increases in CPI inflation throughout all quarters. In addition, the impact of increases in aggregate demand on the UK consumer 
price level is positive and statistically significant from the first year onwards. The maximum is reached three years after the shock occurs. Lastly, the impact of expansions of oil market-specific demand on UK inflation is around zero throughout all quarters.
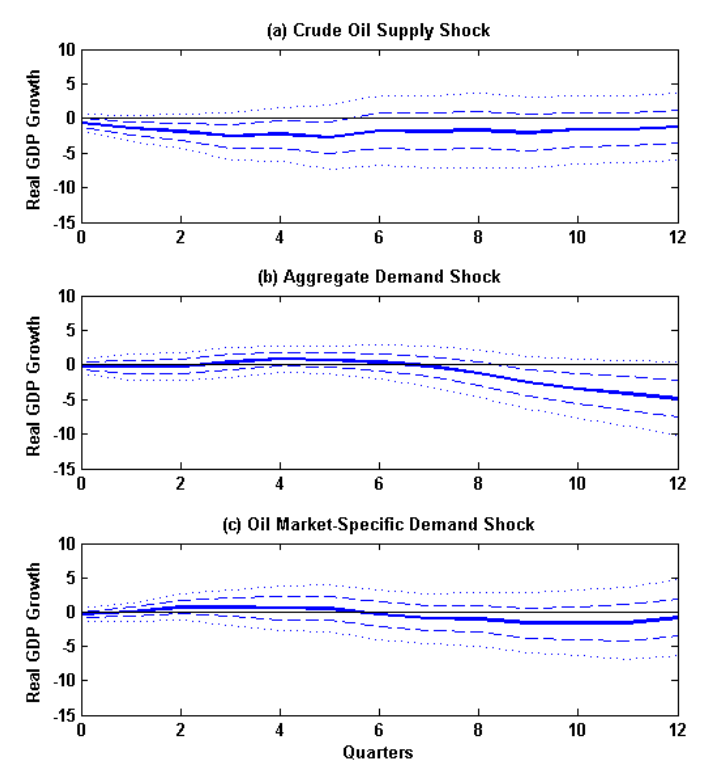
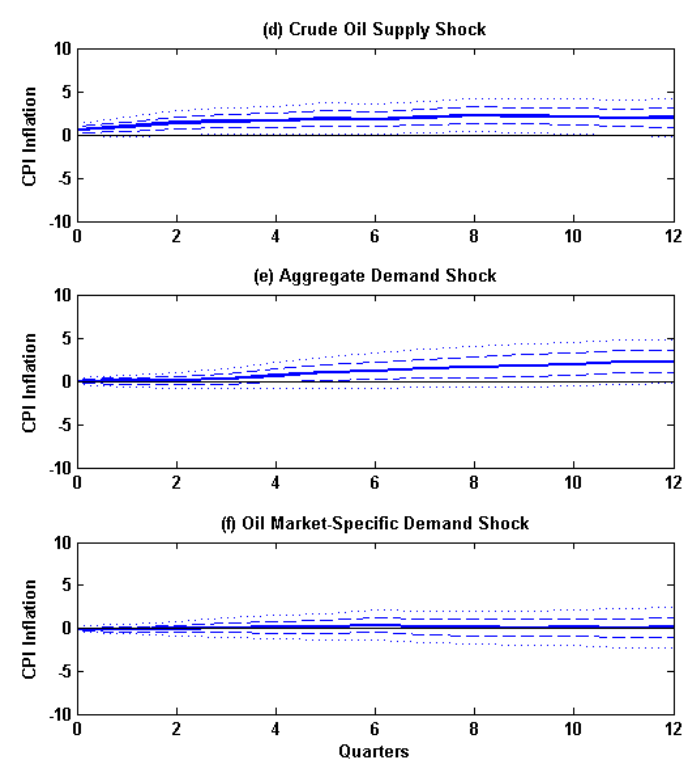

Figure 6: IRFs of the UK Real GDP Growth and CPI Inflation to Each Str. Shock

Note: Solid blue lines: point estimates; dash and dotted blue lines: one and two standard error bands, respectively.

Our results are in accordance with the findings of Millard and Shakir (2013) for the UK economy ${ }^{10}$. In particular, oil supply disruptions induce an immediate fall in GDP growth and cause a sustained increase in inflation.

\footnotetext{
${ }^{10}$ Millard and Shakir (2013) have employed an empirical framework with time-varying parameters in order to understand how the impact of oil price shocks on the UK economy may have developed over time. However, as argued by Kilian (2014), the idea of analysing the responses of several macroeconomic aggregates to oil demand and supply shocks within a time-varying parameter VAR is not practical. Time-varying parameter VARs do not provide an efficient estimation since they consider samples that are not long enough in order to have a sufficient variation in oil demand and oil supply shocks. Moreover, our identifying assumptions hold only using data at monthly frequency. However, it is well documented that, although timevarying parameter VARs work well with quarterly data, they are computationally infeasible when using monthly data.
} 
We find that increases in aggregate demand initially have a negligible effect on UK output growth, but in the long run they tend to depress it, in accordance with the findings of Kilian (2009) for the US economy. This last result can be explained as follows. On impact, positive unexpected global economic shocks stimulate UK real GDP growth and offset the growth-retarding effects of a higher real price of oil. However, as this stimulus disappears over time, the response of UK GDP growth becomes negative. The most relevant example in this concern is the "Great Surge" in the real price of oil between 2002 and mid-2008. During this period, the UK economy did not experience any severe recession because the oil price surge was mainly driven by unexpectedly strong demand for oil from emerging Asia which offset the negative effects of higher oil prices and other imported commodities.

Similarly to the results of Peersman and Van Robays (2012), we find that positive precautionary demand shocks have a very small impact on GDP growth and have no significant effects on domestic inflation. These findings suggest that precautionary demand shocks have small and insignificant effects on domestic GDP growth and CPI inflation because the UK is an oil producer country. That is, the UK economy has been less affected by changes in inventory holdings compared to typical oil importing countries because it had the possibility to increase its own oil production in order to self-insure against interruptions to foreign oil supply instead of drawing upon inventory holdings.

Figure 7 shows the impulse response functions for the UK nominal interest rate (Graphs (a), (b), (c)) and the real government deficit (Graphs (d), (e), (f)) to shocks of oil supply disruptions, aggregate demand and oil market-specific demand.

We observe that the nominal interest rate progressively falls in response to oil supply disruptions (Graphs (a), (b) and (c)). One-standard error confidence intervals indicate that the response of the UK nominal interest rate to this shock is statistically significant starting from the fourth quarter. The increase in aggregate demand induces a positive nominal interest rate, statistically significant from the third quarter onwards. In addition, positive oil specific-market demand shocks 
cause an increase in the nominal interest rate. The positive impact of oil specificmarket demand shocks on the nominal interest rate is statistically significant from the second to the seventh quarter.

We deduce that the Bank of England responds differently to oil price fluctuations associated with unanticipated booms in oil demand with respect to oil price changes due to unexpected oil supply disruptions. This result is consistent with the findings of Peersman and Van Robays (2012). Evidently, these different responses of the monetary authority relate to the corresponding effects of oil demand shocks and oil supply shocks on the UK economy.

For example, as we have shown in Figure 6, an unexpected demand boom driven by the global business cycle does not depress the UK economy in the short run. Conversely, an unanticipated oil supply disruption reduces immediately UK real output growth. This implies different reactions of UK monetary authority depending on the composition of the oil demand and oil supply shocks underlying the oil price shock.

In particular, the evidence shows that the nominal interest rate increases after both an aggregate demand shock and an oil market-specific demand shock. In this regard, the positive response to aggregate demand shocks is consistent with the Bank of England's decision to raise interest rates before the oil price shock of 1978-1980. Indeed, looking at the 3 Month Treasury Bills series, it is evident that the Bank of England had been steadily raising interest rates from mid-1977 to the end of 1980 .

Figure 7 also shows that negative shocks to oil supply induce the Bank of England to decrease the nominal interest rate. This result is in line with the findings of Kilian and Lewis (2011) about the behaviour of the Federal Reserve in the case of negative oil supply shocks. The negative response of the nominal interest rate to unanticipated oil supply disruptions is consistent with the view that the Bank of England considers the resulting oil price increases as adverse demand shocks. 
In response to negative shocks of crude oil supply, the UK government deficit decreases. The one-standard error confidence intervals indicate that the negative response is significant for all the quarters considered. As we can observe from Graph (e), the response of UK government deficit to increases in aggregate demand is not statistically significant at all horizons. Similarly, expansions of oil marketspecific demand have non-significant effects on the UK government deficit. Thus, we conclude that since the UK is an oil producer country, this increase in oil price implies an improvement of government oil revenues and government budget.
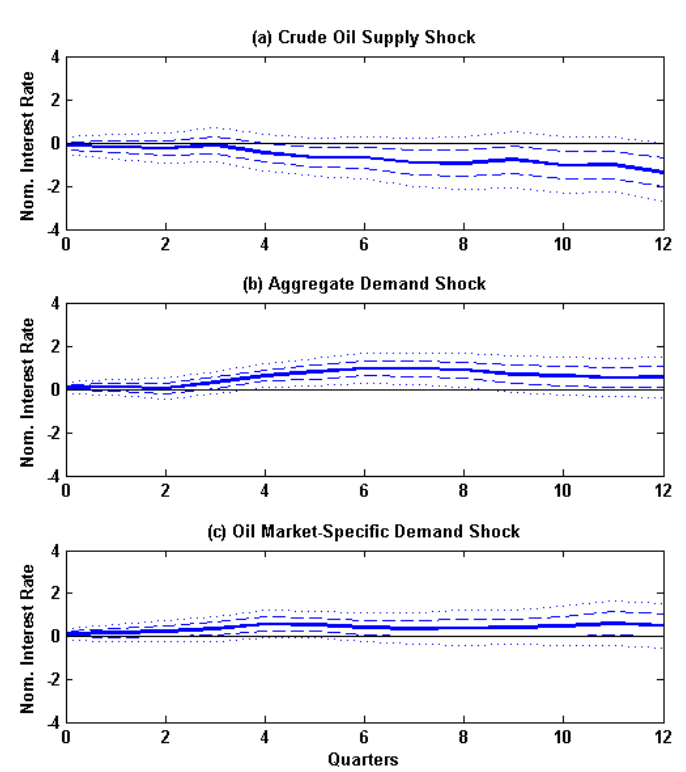
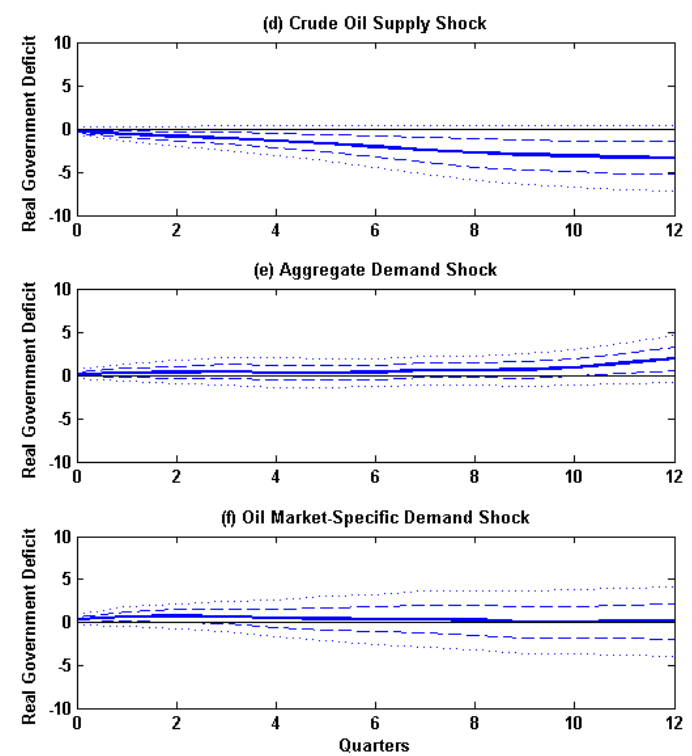

Figure 7: IRFs of the UK Nom. Int. Rate and Gov. Def. to Each Str. Shock

Note: Solid blue lines: point estimates; dash and dotted blue lines: one and two standard error bands, respectively.

Our estimated result is consistent with previous UK literature (see, among the others, Powell and Horton, 1985; Hall et al., 1986; Young, 2000; OECD Economic Surveys, 2002; OBR, 2010; Barrel et al., 2011). All these studies have found that, after an increase in the oil price, the UK fiscal position is positively affected by 
the additional North Sea revenues stemming from the petroleum revenue tax and the VAT applied on oil products. In this regard, Young (2000) argued that in a scenario of high oil price, although the performance of UK economy deteriorates, the government represents one of the few winners in the short term.

\section{Conclusions}

In this paper, we have studied the causes and the consequences of oil price fluctuations on the UK economy. Our empirical approach assumes that the real oil price is endogenous with respect to macroeconomic fundamentals and identifies the causes and consequences of oil price shocks by a two-stage method. In the first stage, we identified shocks to the World oil price from oil supply, aggregate demand and oil market-specific demand. In the second stage, we assessed the impact of structural innovations estimated in the first stage on several UK macroeconomic aggregates such as, real GDP growth, CPI inflation, nominal interest rate and real government deficit.

Several important insights emerge from our analysis. We find that, since the mid-1970s, shortfalls in oil supply have had small effects on oil price changes. Therefore, our results contrast with the view that major oil price changes are caused by disruptions in oil supply triggered by exogenous political events occurring in the Middle East. Instead, we find that major fluctuations in the real oil price coincide with shifts in precautionary demand for oil.

Our IRFs show different responses of UK macroeconomic aggregates depending on the underlying shock affecting oil price. More specifically, GDP growth goes down immediately in response to negative oil supply shocks whereas increases in aggregate demand, initially, have small effects on domestic output growth but, in the long run, they tend to reduce it. In general, our estimated responses show that oil shocks cause a sustained increase in UK inflation.

Focusing on UK monetary policy, we find that the nominal interest rate increases after both aggregate demand shocks and oil market-specific demand 
shocks. The opposite occurs in the case of negative shocks to oil supply. Our estimated responses also indicate that the increase in the real oil price induces an improvement of UK public finances due to the rise in oil revenues.

To conclude, we believe that the empirical approach presented in this paper provides a useful framework in order to understand the causes and the consequences of oil price shocks on the UK economy. Given the promising results of this paper, we consider as a sound extension of this work the development of a DSGE model which is able to distinguish between several causes of fluctuations in the global demand for industrial commodities and to estimate the impact of alternative policy choices. We leave this line of investigation for future research. 


\section{References}

[1] Aastveit, K., Bjørnland, H., \& Thorsrud, L., 2015. "What drives oil prices? Emerging versus developed economies," Journal of Applied Econometrics, Forthcoming.

[2] Alquist, R., \& Kilian, L., 2010. "What do we learn from the price of crude oil futures?," Journal of Applied Econometrics, vol. 25(4), pages 539573.

[3] Apergis, N., \& Miller, S., 2009. "Do structural oil-market shocks affect stock prices?" Energy Economics, vol. 31(4), 569-575.

[4] Barrell, R., Delannoy, A., \& Holland, D., 2011. "The impact of high oil prices on the economy," National Institute Economic Review, vol. 217(F68).

[5] Barsky R., \& Kilian L., 2002. "Do we really know that oil caused the great stagflation? A monetary alternative," Bernanke B, Rogoff K (eds), NBER Macroeconomics Annual 2001, pages 137-183.

[6] Barsky, R., \& Kilian, L., 2004. "Oil and the Macroeconomy Since the 1970s," Journal of Economic Perspectives, vol. 18(4), pages 115-134.

[7] Basher, S., Haug, A., \& Sadorsky, P., 2012. "Oil prices, exchange rates and emerging stock markets." Energy Economics, vol. 34 (1), pages 227240.

[8] Christiane, B., Peersman G., \& Van Robays, I., 2010. "The economic consequences of oil shocks: differences across countries and time," RBA Annual Conference Volume, in: Renée Fry \& Callum Jones \& Christopher Kent (ed.), Inflation in an Era of Relative Price Shocks, Reserve Bank of Australia. 
[9] Baumeister, C., \& Peersman, G., 2013. "The role of time-varying price elasticities in accounting for volatility changes in the crude oil market," Journal of Applied Econometrics, vol. 28(7), pages 1087-1109.

[10] Bernanke, B., 2004. "Oil and the economy," Remarks at the Distinguished Lecture Series, Darton College, Albany, GA, $21^{\text {st }}$ October.

[11] Bernanke, B., Gertler, M., \& Watson, M., 1997. "Systematic monetary policy and the effects of oil shocks," Brookings Papers on Economic Activity, vol. 28(1), pages 91-157.

[12] Berument, M., Ceylan, N., \& Dogan, N., 2010. "The impact of oil price shocks on the economic growth of selected MENA ${ }^{1}$ countries," The Energy Journal, vol. 31, Number 1.

[13] Blanchard, O., \& and Galí, J., 2007. "The Macroeconomic Effects of Oil Price Shocks: Why are the 2000s so different from the 1970s?," NBER Chapters, in: International Dimensions of Monetary Policy, pages $373-421$.

[14] Bodenstein, M., Erceg, C., \& Guerrieri, L., 2008. "Optimal monetary policy with distinct core and headline inflation rates," Journal of Monetary Economics, vol. 55, pages S18-S33.

[15] Bodenstein, M., \& Guerrieri, L., 2011. "Oil efficiency, demand, and prices: a tale of ups and downs," International Finance Discussion Papers 1031, Board of Governors of the Federal Reserve System (US).

[16] Bodenstein, M., Erceg, C., \& Guerrieri, L., 2011. "Oil shocks and external adjustment," Journal of International Economics, vol. 83(2), pages 168-184.

[17] Bodenstein, M., \& Guerrieri, L., \& Kilian, L., 2012. "Monetary Policy Responses to Oil Price Fluctuations," IMF Economic Review, vol. 60(4), pages $470-504$. 
[18] Burbidge, J., \& Harrison, A., 1984. "Testing for the effects of oil-price rises using vector autoregressions," International Economic Review, vol. $25(2)$, pages 459-484.

[19] Gonçalves, S., \& Kilian, L., 2004. "Bootstrapping autoregressions with conditional heteroskedasticity of unknown form," Journal of Econometrics, vol. 123(1), pages 89-120.

[20] Hall, S., Henry, B. \& Herbert, R., 1986. "Oil prices and the economy," National Institute Economic Review, vol. 116(38).

[21] Hamilton, J., 1983. "Oil and the macroeconomy since World War II," Journal of Political Economy, vol. 92 (2), pages 228-248.

[22] Hamilton, J., 2003. "What is an oil shock?" Journal of Econometrics, vol. 113(2), pages 363-98.

[23] Hamilton, J., 2009. "Causes and consequences of the oil shock of 200708," Brookings Papers on Economic Activity, vol. 40(1), pages 215-283.

[24] Kilian, L., 2008. "The economic effects of energy price shocks," Journal of Economic Literature, vol. 46, pages 871-909.

[25] Kilian, L., 2009. "Not all oil price shocks are alike: disentangling demand and supply shocks in the crude oil market," American Economic Review, vol. 99, pages 1053-1069.

[26] Kilian, L., 2014. "Oil price shocks: causes and consequences," Annual Review of Resource Economics, vol. 6(1), pages 133-154.

[27] Kilian, L., \& Hicks B., 2013. "Did unexpectedly strong economic growth cause the oil price shock of 2003-2008?" Journal of Forecasting, vol. 32, pages 385-394. 
[28] Kilian, L., \& Lewis L., 2011. "Does the Fed respond to oil price shocks?" Economic Journal, vol. 121, 1047-1072.

[29] Kilian, L., \& Murphy D., 2012. "Why agnostic sign restrictions are not enough: understanding the dynamics of oil market VAR models," Journal of the European Economic Association, vol. 10, pages 1166-1188.

[30] Kilian, L., \& Murphy, D., 2014. "The role of inventories and speculative trading in the global market for crude oil," Journal of Applied Econometrics, vol. 29(3), pages 454-478.

[31] Klovland, J., 2004. "Business cycles, commodity prices and shipping freight rates: some evidence from the pre-WWI Period," Paper presented at Workshop on Market Performance and the Welfare Gains of Market Integration in History, Florence, Italy.

[32] Lee, K., \& Ni, S., 2002. "On the dynamic effects of oil price shocks: a study using industry level data," Journal of Monetary Economics, vol. 49 , pages $823-852$.

[33] Lombardi, M., \& Van Robays, I., 2011. "Do financial investors destabilize the oil price?," Working Paper Series 1346, European Central Bank.

[34] Milani, F., 2009. "Expectations, learning and the changing relationship between oil prices and the macroeconomy," Energy Economics, vol. 31, 827-837.

[35] Millard, S., \& Shakir, T., 2013. "Oil shocks and the UK economy: the changing nature of shocks and impact over time," Bank of England working papers 476.

[36] Morana, C., 2013. "The oil price-macroeconomy relationship since the mid-1980s: a global perspective," The Energy Journal, vol. 34, Number 3. 
[37] Nakov, A., \& Pescatori, A., 2010. "Oil and the great moderation," Economic Journal, Royal Economic Society, vol. 120(543), pages 131-156.

[38] Nakov, A., \& Nuño, G., 2011. "A general equilibrium model of the oil market," Banco de España Working Papers 1125, Banco de España.

[39] Papapetrou, E., 2001. "Oil price shocks, stock market, economic activity and employment in Greece." Energy Economics, vol. 23(5), pages 511-532.

[40] Peersman, G., 2005. "What caused the early millennium slowdown? Evidence based on vector autoregressions," Journal of Applied Econometrics, vol. 20(2), pages 185-207.

[41] Peersman, G., \& Van Robays, I., 2009. "Oil and the Euro area economy," Economic Policy, vol. 24(60), pages 603-651.

[42] Peersman, G., \& Van Robays, I., 2012. "Cross-country differences in the effects of oil shocks," Energy Economics, vol. 34(5), pages 1532-1547.

[43] Office for Budget Responsibility, 2010. "Assessment of the effect of oil price fluctuations on the public finances".

[44] Organization for Economic Cooperation and Development, 2002. "The reverberations of the oil price shock" OECD Economic Surveys - United Kingdom - Annex III.

[45] Powell, S. \& Horton, G., 1985. "The economic effects of lower oil prices," GES Working Paper, no. 76 (Treasury Working paper, no. 34).

[46] Young, G., 2000. "The effects of higher oil prices on the UK economy," National Institute Economic Review, vol. 174(8). 


\section{Appendix A: Data}

$\Delta \operatorname{prod}_{t}$ : as we described in the main body of the paper, this is the percentage change of global crude oil production. This series is obtained by the log differences of world crude oil production in millions per barrels pumped per day (averaged by month). The source is the US Department of Energy.

$r e a_{t}$ : as we described in the main body of the paper, this is the index of the global real economic activity. The source of this series is Kilian website: http://www-personal.umich.edu/ lkilian/reaupdate.txt.

Kilian (2009) provides a clear explanation in order to obtain $r e a_{t}$. In particular, the data series to construct this index are taken from representative singlevoyage freight rates available in the monthly report on "Shipping Statistics and Economics" published by Drewry Shipping Consultants Ltd. These data series relate to various bulk dry cargoes consisting of grain, oilseeds, coal, iron ore, fertilizer and scrap metal. In order to eliminate the fixed effects for different routes, commodities and ship sizes, Kilian adopts two steps. Firstly, he computes the period-to-period growth rates for each series. Secondly, he takes the equalweighted average of these growth rates and cumulates the average growth rate. The final series is deflated by the US CPI and linearly detrended. The base month is January 1986. Kilian also provides evidence that this index based on industrial commodity markets well represents the level of global real economic activity.

$r p o_{t}$ : as we described in the main body of the paper, this is the real price of oil and it is expressed in log terms. This series is obtained from the refiner acquisition cost of imported crude oil. The source is US Department of Energy. The nominal series of oil price is deflated by the US CPI. The source is the US Bureau of Economic Analysis.

$\Delta y_{t}$ : it is the growth rate of UK real GDP. This series is obtained by the log differences of real UK GDP: "gross domestic product, chained volume measures, seasonally adjusted (£m)". The source is Office for National Statistics (code ABMI in Quarterly National Accounts). 
$\pi_{t}$ : it is the UK CPI inflation. This series is obtained by the log differences of UK consumption expenditure deflator: "final consumption expenditure by household and NPISH deflator, seasonally adjusted (base period: 2011)". The source is Office for National Statistics (code YBFS in Quarterly National Accounts).

$\Delta r_{t}$ : it is the UK short-term nominal interest rate. This series is obtained by the 3 month treasury bills: "quarterly average rate of discount, 3 month treasury bills (Sterling)". The source is Bank of England (code IUQAAJNB in Statistical Interactive Database).

$d_{t}$ : it is the UK real government deficit. This series is obtained by the "central government net cash requirement, current price, not seasonally adjusted, (£m)". The source is Office for National Statistics (code RUUW in Quarterly National Accounts). The original series is seasonally adjusted and deflated by the final consumption expenditure by household and NPISH deflator. 